See Article page 2046.

\section{Commentary: When less is not more -volume-outcome relationships in aortic valve replacement}

Derrick Y. Tam, MD, PhD, Dinela Rushani, MD, MSc, and Stephen E. Fremes, MD, MSc

Although surgical aortic valve replacement (SAVR) was previously the gold standard for the management of symptomatic aortic stenosis in patients who were acceptable surgical candidates, transcatheter aortic valve replacement (TAVR) has evolved from the main therapy for inoperable and highrisk patients to a reasonable option in intermediate-risk patients. ${ }^{1}$ In low-risk patients, TAVR was shown to be noninferior compared with surgery, receiving Food and Drug Administration approval in low-risk patients. Clinical trials showed excellent early outcomes for both TAVR $(<1 \%$ mortality) and SAVR ( $\sim 1 \%$ mortality); as such, moving forward, we expect outcomes for SAVR to be scrutinized and compared with TAVR, particularly in patients at low surgical risk. $^{2,3}$ As the number of patients undergoing TAVR continues to increase, the volume of SAVR will decrease, and whether SAVR should be performed at high-volume centers or centers of excellence becomes an increasingly relevant question.

In this issue of the Journal, Dewey and colleagues ${ }^{4}$ use the Texas Quality Initiative, a collaborative of 29 hospitals that perform cardiac surgical procedures in North Texas, to better understand the volume-outcome relationship for isolated SAVR in low-risk patients. Over a period of 5 years, from 2012 to 2017, hospitals were dichotomized into low

\footnotetext{
From the Division of Cardiac Surgery, Schulich Heart Centre, Department of Surgery, Sunnybrook Health Sciences Centre, University of Toronto, Toronto, Ontario, Canada.

Disclosures: The authors reported no conflicts of interest.

The Journal policy requires editors and reviewers to disclose conflicts of interest and to decline handling or reviewing manuscripts for which they may have a conflict of interest. The editors and reviewers of this article have no conflicts of interest.

Received for publication July 21, 2020; revisions received July 21, 2020; accepted for publication July 22, 2020; available ahead of print July 25, 2020.

Address for reprints: Stephen E. Fremes, MD, MSc, Schulich Heart Centre, Sunnybrook Health Sciences Centre, 2075 Bayview Ave, Room H4 05, Toronto, Ontario M4N 3M5, Canada (E-mail: stephen.fremes@sunnybrook.ca).

J Thorac Cardiovasc Surg 2022;163:2053-5

$0022-5223 / \$ 36.00$

Copyright (c) 2020 by The American Association for Thoracic Surgery

https://doi.org/10.1016/j.jtcvs.2020.07.068
}

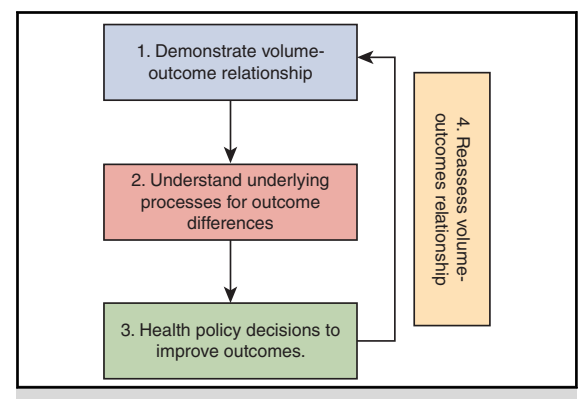

A framework to improving outcomes at low-volume institutions.

\author{
CENTRAL MESSAGE \\ Efforts should be made to miti- \\ gate the low volume-worse \\ outcomes relationship in pa- \\ tients undergoing aortic valve \\ replacement while preserving \\ patients' access to care.
}

volume ( $<200$ cases over 5 years) or high volume $(\geq 200$ cases). Inverse probability of treatment weighting was used to balance 26 baseline characteristics. Outcomes after inverse probability of treatment weighting were different between the low-volume and high-volume hospitals with an almost doubling in the odds of mortality in lowvolume hospitals (odds ratio [OR], 1.95; 95\% confidence interval $[\mathrm{CI}], 1.20-3.20)$ along with a higher risk of renal failure (OR, 2.25; 95\% CI, 1.33-3.81) and 30-day readmission (OR, 1.61; 95\% CI, 1.27-2.04). Taken together, these findings suggest that early outcomes after SAVR are better at high-volume hospitals compared with lowvolume hospitals.

However, these findings must be interpreted in the context of some important study limitations, some of which have already been highlighted by the authors. The key limitation is that unmeasured or unknown confounders may bias the findings. At the patient level, determinants of outcomes such as socioeconomic status and frailty were not measured. The relationship between an individual surgeon's volume and outcomes was also not assessed. A surgeon's volume depends on the institution's volume and the number of surgeons in the hospital. As such, a surgeon at a lowvolume hospital may still perform more SAVRs than one in a high-volume center staffed by more surgeons. It is 
also possible that surgeons could work at more than 1 center, such that patients at a low-volume center may be treated by a high-volume surgeon. Previous work by the same authors found that higher surgeon volume was associated with improved SAVR outcomes. ${ }^{5}$ Another limitation of the study is the exclusion of concomitant procedures such as coronary artery bypass grafting. This can not only affect the definition of "volume" but also limit generalizability because patients requiring concomitant surgery may represent an increasing proportion of patients undergoing SAVR as those with isolated aortic stenosis may be preferentially treated with TAVR. Furthermore, given the significance for policy-making, a more precise quantification of the volume-outcome relationship is necessary. The cutoff of 200 cases to denote low- versus high-volume institutions seems arbitrary; volume measured as a continuous variable would be more informative to statistically explore the underlying relationship with outcomes. Finally, the applicability of these results may be limited to the United States, where the annual median of cases in low-volume hospitals is very low. ${ }^{6}$

Although the volume-outcome relationship is pervasive throughout surgery and typically affects procedures that are complex and infrequent, interestingly, this relationship has also been demonstrated in cardiac surgery for some of the most commonly performed procedures, such as coronary surgery, SAVR, and mitral valve repair. ${ }^{7-10}$ This study adds to the literature and shows that in low-risk patients, procedural volume remains important to improving early outcomes. A volume-outcome relationship was also explored for TAVR using the Transcatheter Valve Therapy Registry of 555 hospitals. TAVR procedures showed higher mortality and more variation in low-volume hospitals compared with higher-volume hospitals. ${ }^{11}$ Similar findings were seen in New York State with less postprocedural stroke in patients undergoing TAVR treated by experienced operators. ${ }^{12}$

However, the policy implications of this study are complex. Although regionalization of surgical procedures to high-volume centers may improve outcomes, this raises competing concerns over equity and access to care, particularly as rural and underserved populations are disproportionately affected. As such, it may be more practical to understand and intervene in the pathways that improve outcomes at lower-volume centers. Preoperatively, optimal patient selection may improve outcomes. Previous work has shown that hospitals with a TAVR program had better surgical outcomes, likely as a result of improved patient selection by the heart team. ${ }^{13}$ Gonzalez and colleagues $^{14}$ have shown that major complication rates postoperatively were similar between high- and lowvolume centers, whereas failure-to-rescue rates were higher in low-volume centers, leading to greater mortality. Thus, care pathways to improve the early recognition and treatment of major complications after surgery may reduce perioperative mortality at low-volume centers. The Michigan Society of Thoracic and Cardiovascular Surgeons Quality Collaborative includes 33 hospitals of various sizes that participate in quarterly in-person meetings to discuss statewide quality improvement initiatives by examining individual hospital data in an unblinded manner and has led to protocol changes resulting in less postoperative complications. ${ }^{15}$ Another possible solution to improve outcomes at lower-volume centers would be to facilitate heart-team discussions and collaboration with more experienced highvolume centers to share expertise and help in decisionmaking regarding patient selection, treatment, and development of standardized postoperative pathways to optimize management of potential complications. The impact of these interventions should be evaluated and the volumeoutcome relationship reassessed. While oftentimes "less is more," when it comes to aortic valve replacement, volume and experience matter in optimizing outcomes for patients with aortic valve disease. Efforts should be made to mitigate the low volume-worse outcomes relationship in patients undergoing aortic valve replacement while preserving access to care.

\section{References}

1. Nishimura RA, Otto CM, Bonow RO, Carabello BA, Erwin JP III, Fleisher LA, et al. 2017 AHA/ACC focused update of the 2014 AHA/ ACC guideline for the management of patients with valvular heart disease: a report of the American College of Cardiology/American Heart Association Task Force on Clinical Practice Guidelines. J Am Coll Cardiol. 2017;70: 252-89.

2. Popma JJ, Deeb GM, Yakubov SJ, Mumtaz M, Gada H, O'Hair D, et al. Transcatheter aortic-valve replacement with a self-expanding valve in low-risk patients. N Engl J Med. 2019;380:1706-15.

3. Mack MJ, Leon MB, Thourani VH, Makkar R, Kodali SK, Russo M, et al. Transcatheter aortic-valve replacement with a balloon-expandable valve in low-risk patients. N Engl J Med. 2019;380:1695-705.

4. Dewey TM, Herbert MA, Prince SL, Bowers BS. Influence of surgical volume on outcomes in low risk patients having isolated surgical aortic valve replacement. $J$ Thorac Cardiovasc Surg. 2022;163:2046-52.e2.

5. Dewey TM, Herbert MA, Ryan WH, Brinkman WT, Smith R, Prince SL, et al. Influence of surgeon volume on outcomes with aortic valve replacement. Ann Thorac Surg. 2012;93:1107-13.

6. Tam DY, Rocha RV, Wijeysundera HC, Austin PC, Dvir D, Fremes SE. Surgical valve selection in the era of transcatheter aortic valve replacement in the Society of Thoracic Surgeons Database. J Thorac Cardiovasc Surg. 2019; 159:416-27.E8.

7. Hannan EL, O’Donnell JF, Kilburn H Jr, Bernard HR, Yazici A. Investigation of the relationship between volume and mortality for surgical procedures performed in New York State Hospitals. JAMA. 1989;262:503-10.

8. Benedetto U, Lau C, Caputo M, Kim L, Feldman DN, Ohmes LB, et al. Comparison of outcomes for off-pump versus on-pump coronary artery bypass grafting in low-volume and high-volume centers and by low-volume and high-volume surgeons. Am J Cardiol. 2018;121:552-7.

9. Chikwe J, Toyoda N, Anyanwu AC, Itagaki S, Egorova NN, Boateng P, et al. Relation of mitral valve surgery volume to repair rate, durability, and survival. J Am Coll Cardiol. 2017;69:2397-406.

10. Birkmeyer JD, Siewers AE, Finlayson EV, Stukel TA, Lucas FL, Batista I, et al. Hospital volume and surgical mortality in the United States. N Engl J Med. 2002; 346:1128-37.

11. Vemulapalli S, Carroll JD, Mack MJ, Li Z, Dai D, Kosinski AS, et al. Procedural volume and outcomes for transcatheter aortic-valve replacement. $N$ Engl J Med. 2019;380:2541-50. 
12. Salemi A, Sedrakyan A, Mao J, Elmously A, Wijeysundera H, Tam DY, et al. Individual operator experience and outcomes in transcatheter aortic valve replacement. JACC Cardiovasc Interv. 2019;12:90-7.

13. Kundi H, Strom JB, Valsdottir LR, Elmariah S, Popma JJ, Shen C, et al. Trends in isolated surgical aortic valve replacement according to hospital-based transcatheter aortic valve replacement volumes. JACC Cardiovasc Interv. 2018;11: 2148-56.
14. Gonzalez AA, Dimick JB, Birkmeyer JD, Ghaferi AA. Understanding the volume-outcome effect in cardiovascular surgery: the role of failure to rescue JAMA Surg. 2014;149:119-23.

15. Likosky DS, Harrington SD, Cabrera L, DeLucia A 3rd, Chenoweth CE, Krein SL, et al. Collaborative quality improvement reduces postoperative pneumonia after isolated coronary artery bypass grafting surgery. Circ Cardiovasc Qual Outcomes. 2018;11:e004756.
See Article page 2046.

\section{Commentary: The importance of surgical case volume in the transcatheter era}

\author{
Pedro Catarino, MD, FRCS, Dominick Megna, MD, \\ and Joanna Chikwe, MD, FRCS
}

What cardiac surgeon does not enjoy performing a low-risk aortic valve replacement (AVR)? The patients really benefit and are appreciative. The surgery is quick and within every surgeon's technical comfort zone. It is often the first procedure over which a teacher and pupil bond. Exposure is generally excellent, allowing both teacher and trainee to be facile. However, indications for transcatheter aortic valve replacement (TAVR), which already include high- and intermediate-risk populations, are expanding to include low-risk patients. Most surgeons can claim zero mortality in low-risk patients. Unfortunately, this does not mean they have cracked the surgical holy grail; rather, they have not done enough cases yet, as the paper by Dewey and colleagues in this issue of the Journal shows. ${ }^{1}$

To evaluate the impact of case volume, the authors used a regional Society of Thoracic Surgeons database to identify

\footnotetext{
From the Department of Cardiac Surgery, Smidt Heart Institute, Cedars-Sinai Medical Center, Los Angeles, Calif.

Disclosures: Cedars-Sinai Medical Center receives honoraria from EdwardsLifesciences and Medtronic for speaker and consulting activity. The authors reported no conflicts of interest.

The Journal policy requires editors and reviewers to disclose conflicts of interest and to decline handling or reviewing manuscripts for which they may have a conflict of interest. The editors and reviewers of this article have no conflicts of interest.

Received for publication July 22, 2020; revisions received July 22, 2020; accepted for publication July 23, 2020; available ahead of print July 25, 2020.

Address for reprints: Joanna Chikwe, MD, FRCS, Department of Cardiac Surgery, Smidt Heart Institute, Cedars-Sinai Medical Center, Beverly Hills, Los Angeles, CA (E-mail: joanna.chikwe@cshs.org).

J Thorac Cardiovasc Surg 2022;163:2055-6 $0022-5223 / \$ 36.00$

Copyright (c) 2020 Published by Elsevier Inc. on behalf of The American Association for Thoracic Surgery

https://doi.org/10.1016/j.jtcvs.2020.07.076
}

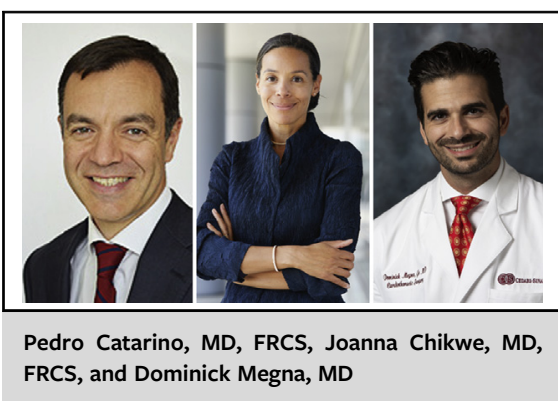

CENTRAL MESSAGE

Heart-team performance and appropriateness of care may have a greater impact on patient outcomes than case volume in the transcatheter era.

2066 low-risk patients who underwent isolated AVR. Centers performing more than 200 cases annually were classified as high-volume, whereas those performing fewer were classified as low volume. Just 3 of 29 hospitals in North Texas were high-volume, treating more than one half the patient population $(53 \%)$. The study revealed greater mortality in the low-volume cohort compared with the high-volume cohort (hazard ratio, 1.95; 95\% confidence interval, 1.2-3.2). Other quality surrogates also favored high-volume centers: postoperative renal failure, permanent pacemaker requirement, transfusion, and readmission rates.

Why is this? The authors highlight several factors, emphasizing institutional processes and resources, and "failure to rescue." The most resilient hospitals have robust processes and depth of staff, resulting in the ability to rescue patients who develop complications that might otherwise amplify into significant adverse outcomes, including mortality. ${ }^{2}$ There are just 3 centers in the high-volume group, which could be centers of excellence independently of 